\title{
SALE MODELING IN AN ALGERIAN INDUSTRIAL FIRM: LOOKING INTO POSSIBLE APPLICATIONS USING BOX AND JENKINS METHODOLOGY
}

\author{
Latifa Djebbari, PhD \\ University of Tlemcen, Algeria \\ E-mail: dlatefa@yahoo.fr
}

\begin{abstract}
This study aims at applying Box - Jenkins analysis for time series to forecast sales in short term, which is considered as one of fundamental indicators necessary for taking important and strategic decisions for the Algerian industrial firm Denitex. This is in addition to its use in guiding the exploitation of the scare sources within the factory after analysing the previous sailings. The proposed model is characterized by many features; the most important one is the realism of its assumptions that make forecasts more reliable and accurate than any other forecasting models.
\end{abstract}

\section{KEY WORDS}

Forecasting sales, Box and Jenkins, Taking decisions.

One of the most confusing imbalances in the Algerian sectors seems to be at the textile sector, which appears to suffer from the consequences of economic liberalization and the entry of foreign competition, in addition to the absolute dependence of the global market on importing raw materials.

Under a number of circumstances created by the new economic changes in the Algerian sectors; and due to the invasion of Chinese, Turkish and other acceptable products in terms of quality and affordable prices that fit the purchasing power of consumers, the Algerian company DENITEX faced major problems to establish a balance between the high levels of competition, the required quality and time.

The company is based on previous studies which date back to the seventies, and was namely related to the technical studies for fabrics and production requirements in addition to other studies concerning the internal arrangement of workshops and special studies and other supply.

Thus, this paper aims to prepare for each type of fabrics produced by this institution and that takes into account the internal and external variables that affect the sales forecasting models, in an attempt to rationalize what rationalization and uses this institution and look to the future sales. Therefore, the following problematic will be raised: How may the Algerian Industrial Foundation DENITEX forecast using BOX and JENKINS methods in order to rationalize the use?

\section{DENITEX FOUNDATION: GENERAL OVERVIEW}

The emergence of industrial company dates back to 1974, it was considered as an important industrial unit of the National Foundation SONITEX in Algeria. After the restructuring of the institution in 1982 in accordance with decision $N{ }^{\circ} 82-399$, dated in December 4, 1982. This industrial complex became part of the COTITEX national economic company and launched in the practice of productive activities in accordance with the theory of production capacity estimated at:

- 2 million tons per year for spinning

- 6 million linear meters per year for weaving.

- 6 million linear meters for finishing.

Its main activity is the basic production and marketing of textile products (100\%) in addition to cotton and blended cotton and polyester.

DENITEX Basic Industrial Products Unit. The main activity of this unity in the production of cotton products or blended between cotton and polyester, and this topic is the core products are as follows: 
Table 1 - Various Consumables Products

\begin{tabular}{|c|c|c|c|c|}
\hline $\mathrm{n} / \mathrm{n}$ & Jeans Products & Gabardine Product & Satin Products & Tarpaulin Products \\
\hline Cotton & $599.64 \mathrm{G} / \mathrm{m}$ & $\begin{array}{r}113.86 \\
\mathrm{G} / \mathrm{M}\end{array}$ & $300 \mathrm{G}$ & $\begin{array}{r}401.90 \\
\mathrm{G} / \mathrm{M}\end{array}$ \\
\hline Polyester & 00 & $\begin{array}{r}231.18 \\
\mathrm{G} / \mathrm{M}\end{array}$ & $\begin{array}{l}168 \\
G / M\end{array}$ & 00 \\
\hline The cost of labor & $11.60 \mathrm{AD}$ & $\begin{array}{r}10.90 \\
D / G\end{array}$ & $\begin{array}{r}11.93 \\
\mathrm{AD}\end{array}$ & $\begin{array}{l}11.06 \\
A D / G\end{array}$ \\
\hline $\begin{array}{l}\text { The cost of colored } \\
\text { materials and } \\
\text { chemicals }\end{array}$ & $61.60 \mathrm{AD}$ & $\begin{array}{r}15.33 \\
\text { AD }\end{array}$ & $\begin{array}{r}43.97 \\
\text { AD }\end{array}$ & $\begin{array}{l}68.12 \\
\mathrm{AD} / \mathrm{G}\end{array}$ \\
\hline Energy & 2.50AD & $\begin{array}{r}2.03 \\
\mathrm{AD} / \mathrm{G}\end{array}$ & $\begin{array}{r}2.23 \\
A D\end{array}$ & $\begin{array}{r}2.50 \\
\mathrm{AD} / \mathrm{G}\end{array}$ \\
\hline Product cost & $M / 153.80$ & $\begin{array}{r}141.62 \\
A D / G\end{array}$ & $\begin{array}{r}220.80 \\
A D\end{array}$ & $\begin{array}{r}176.00 \\
A D\end{array}$ \\
\hline Profit margin & 66.20 & $\begin{array}{r}58.38 \\
A D \\
\end{array}$ & $\begin{array}{r}39.20 \\
A D \\
\end{array}$ & $\begin{array}{r}24.00 \\
\mathrm{AD} \\
\end{array}$ \\
\hline
\end{tabular}

DENITEX: forecasting Realities. The commercial department is the first responsible of preparing the prediction of sales at this institution, it is based on the use of the past sales of the previous years as well as on the assumption that the future is an extension of the past. Therefore, this research will try, based on mathematical and statistical methods of the past sales, to apply a prediction of future sales at this institution in order to rationalise the use of raw materials and energy.

\section{MODELLING SALES}

The time series of the Tarpaulin sales analysis and forecasting. Before addressing the process to forecast sales of this product, we should draw the curve graph of monthly time series for this product, based on an accounting information provided by the managers of this institution and described in the table below. These data are taken during the period from 2003 to 2007 and EVIEWS program version 5.1 was used as a means as follows:

Table 2 - Tarpaulin Monthly sales data (Unit: meter linear)

\begin{tabular}{|l|l|l|l|l|l|l|l|l|l|l|l|l|}
\hline Tarpaulin & January & February & March & April & May & June & July & August & September & October & November & December \\
\hline 2003 & 848 & 2036 & 2994 & 2298 & 5570 & 9777 & 1576 & 889 & 840 & 1554 & 1146 & 1247 \\
\hline 2004 & 1118 & 4020 & 1435 & 3840 & 300 & 2785 & 625 & 2220 & 1140 & 1146 & 846 & 1990 \\
\hline 2005 & 1680 & 1986 & 1095 & 1471 & 5040 & 244 & 36 & 82 & 22 & 635 & 720 & 11772 \\
\hline 2006 & 1216 & 6922 & 2131 & 2106 & 5152 & 5540 & 6397 & 1849 & 1650 & 120 & 354 & 3365 \\
\hline 2007 & 6590 & 2058 & 618 & 5640 & 1589 & 720 & 916 & 1219 & 0 & 2220 & 540 & 128 \\
\hline
\end{tabular}

Based on this table, the following graph is adopted using Eviews 5.1 to represent monthly sales program:

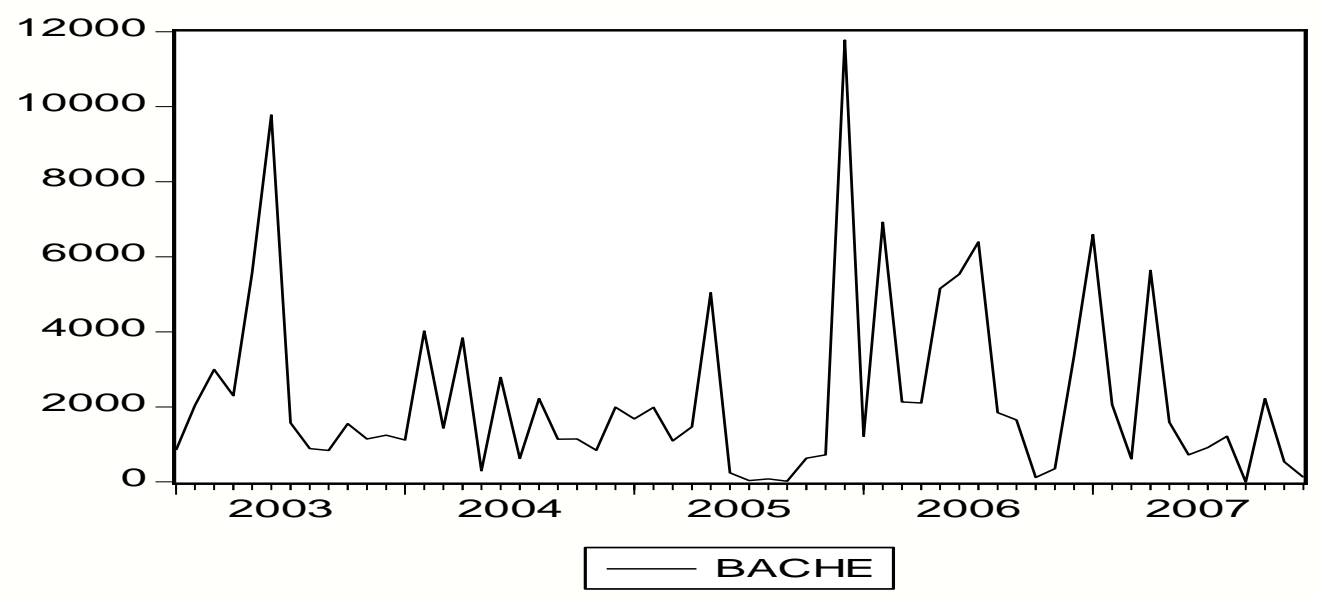

Figure 1 - Tarpaulin evolution of the sales 2003 to 2007 
Throughout this chart, it is clearly noted that the volatility may be due to the presence of seasonality and random changes so we will analyze the time series to determine the real causes of this volatility. Thud, we draw the autocorrelation and partial correlation statement to identify the type of model adopted:

\begin{tabular}{|c|c|c|c|c|c|c|c|c|}
\hline \multicolumn{9}{|c|}{$\begin{array}{l}\text { Sample: 2003M01 2007M12 } \\
\text { Included observations: } 60\end{array}$} \\
\hline \multicolumn{2}{|c|}{ Autocorrelation } & \multicolumn{2}{|c|}{ Partial Correlation } & \multicolumn{2}{|r|}{$\mathrm{AC}$} & PAC & Q-Stat & Prob \\
\hline 1 & 1 & 1 & 1 & 1 & ㅁ. 106 & ㅁ. 106 & 0.7095 & 0.400 \\
\hline 1 & $\mathbf{I}$ & & $\mathbf{I}$ & 2 & D. 124 & D. 114 & 1.6925 & 0.429 \\
\hline 1 & 1 & 10 & $\mathbf{I}$ & 3 & -0.053 & -0.078 & 1.8726 & 0.599 \\
\hline 1 & 1 & 1 & 1 & 4 & -0.076 & -0.080 & 2.2559 & 0.689 \\
\hline 14 & 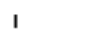 & 1 & 1 & 5 & -0.070 & -0.040 & 2.5831 & 0.764 \\
\hline I & 1 & $\mathbf{I}$ & I & 6 & 0.000 & 0.028 & 2.5831 & 0.859 \\
\hline 1 & $\mathbf{I}$ & 1 & 1 & 7 & D. 146 & 0. 155 & 4.0843 & 0.770 \\
\hline $1-$ & I & $1 \square$ & 1 & 8 & -0.097 & -0.150 & 4.7593 & 0.783 \\
\hline 1 & 1 & 1 & 1 & 9 & -0.006 & -0.032 & 4.7623 & 0.855 \\
\hline 1 & 1 & 1 & 1 & 10 & -0.036 & 0.017 & 4.8561 & 0.901 \\
\hline 1 & 1 & 1 & 1 & 11 & -0.059 & -0.041 & 5.1188 & 0.925 \\
\hline 1 & 1 & I & 1 & 12 & 0.000 & 0.016 & 5.1188 & 0.954 \\
\hline 10 & 1 & 1 & 1 & 13 & 0.078 & 0.071 & 5.6057 & 0.959 \\
\hline 1 & I & 1 & 1 & 14 & 0.015 & -0.038 & 5.6231 & 0.975 \\
\hline 1 ㄷ & 1 & $1 \square$ & 1 & 15 & -0.146 & -0.148 & 7.3891 & 0.946 \\
\hline 10 & $\mathbf{I}$ & 1 & 1 & 16 & -0.026 & 0.001 & 7.4485 & 0.964 \\
\hline 1 & I & $1 \square$ & 1 & 17 & -0.235 & -0.197 & 12.213 & 0.787 \\
\hline $1 \square$ & 1 & 1 С & 1 & 18 & -0.140 & -0.098 & 13.944 & 0.733 \\
\hline $1 \square$ & I & $1 \square$ & 1 & 19 & -0.200 & -0.184 & 17.555 & 0.552 \\
\hline 10 & $\mathbf{I}$ & 10 & 1 & 20 & 0.055 & 0.053 & 17.840 & 0.598 \\
\hline $1 \square$ & 1 & $1 \square$ & 1 & 21 & -0.168 & -0.194 & 20.536 & ㅁ. 488 \\
\hline 1 & 1 & 1 & 1 & 22 & 0.029 & 0.022 & 20.619 & 0.544 \\
\hline 5 & 1 & I & I & 23 & 0.070 & 0.040 & 21.118 & 0.574 \\
\hline 1 & I & 1 & 1 & 24 & -0.030 & -0.029 & 21.211 & 0.626 \\
\hline 1 & I & 1 무 & 1 & 25 & -0.054 & -0.127 & 21.519 & 0.663 \\
\hline 14 & I & 14 & 1 & 26 & -0.062 & -0.071 & 21.939 & 0.692 \\
\hline 14 & 1 & 1 단 & 1 & 27 & -0.060 & -0.122 & 22.347 & 0.720 \\
\hline 1 미 & 1 & 1 ப & I & 28 & -0.101 & -0.063 & 23.537 & 0.706 \\
\hline
\end{tabular}

Figure 2 - Autocorrelation and partial correlation statement of Tarpaulin

We note that some of the autocorrelation coefficients seem to be outside the limits of critical region and this means that there is a seasonal effect, that needs to be removed before forecasting. Then we need to study the stationary of these time series to be able to apply the method of Box Jenkins that require the presence of a stable time series.

Removing the seasonal component from the time series of Tarpaulin. Using Eviews 5.1 program we remove seasonal component using moving averages, that will allows us to study the time series independently of the seasonal component.we symbolize the adjusted series as Tarpaulin CVS and the seasonal coefficients as CS.

Table 3 - Seasonal coefficients of the Time Series of Tarpaulin Sales

\begin{tabular}{|c|c|}
\hline \multicolumn{2}{|c|}{$\begin{array}{l}\text { Ratio to Moving Average } \\
\text { Original Series: BACHE } \\
\text { Adjusted Series: BACHESA }\end{array}$} \\
\hline \multicolumn{2}{|c|}{ Scaling Factors: } \\
\hline 1 & 1.460715 \\
\hline 2 & 1.968213 \\
\hline 3 & 0.745794 \\
\hline 4 & 1.992115 \\
\hline 5 & 1.884029 \\
\hline 6 & 1.110869 \\
\hline 7 & 0.872631 \\
\hline 8 & 0.656646 \\
\hline 9 & 0.464438 \\
\hline 10 & 0.481517 \\
\hline 11 & 0.407045 \\
\hline 12 & 2.144543 \\
\hline
\end{tabular}


The following graph represents the autocorrelation and partial correlation of Tarpaulin CVS as demonstrated below:

Table 4 - Autocorrelation of the series of Tarpaulin CVS

\begin{tabular}{|c|c|c|c|c|c|c|c|c|}
\hline \multicolumn{9}{|c|}{$\begin{array}{l}\text { Sample: } 2003 \text { M01 2007M12 } \\
\text { Included observations: } 60\end{array}$} \\
\hline \multicolumn{2}{|c|}{ Autocorrelation } & \multicolumn{2}{|c|}{ Partial Correlation } & \multicolumn{2}{|r|}{$\mathrm{AC}$} & PAC & Q-Stat & Prob \\
\hline 15 & & 15 & $\square$ । & 1 & 0.135 & 0.135 & 1.1527 & 0.283 \\
\hline 1 & & 1 & 1 & 2 & 0.027 & 0.008 & 1.1981 & 0.549 \\
\hline & 1 & 1 & 1 & 3 & 0.064 & 0.060 & 1.4613 & 0.691 \\
\hline I & 1 & 1 & 1 & 4 & 0.005 & -0.012 & 1.4630 & 0.833 \\
\hline & 1 & 1 & 1 & 5 & -0.038 & -0.040 & 1.5606 & 0.906 \\
\hline & 1 & 1 & 1 & 6 & 0.060 & 0.068 & 1.8097 & 0.936 \\
\hline & I & 15 & $\square$ । & 7 & 0.144 & 0.132 & 3.2696 & 0.859 \\
\hline 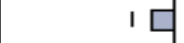 & 1 & $1 \square$ & I & 8 & -0.141 & -0.182 & 4.6886 & 0.790 \\
\hline 1 & 1 & 1 & 1 & 9 & 0.014 & 0.050 & 4.7021 & 0.859 \\
\hline $1 \square$ & 1 & $\mathrm{\square}$ & 1 & 10 & -0.187 & -0.225 & 7.3133 & 0.696 \\
\hline$\square$ & 1 & 14 & 1 & 11 & -0.244 & -0.178 & 11.834 & 0.376 \\
\hline$\square$ & 1 & $1 \square$ & 1 & 12 & -0.241 & -0.206 & 16.327 & 0.177 \\
\hline 1 & 1 & 1 & 1 & 13 & -0.010 & 0.040 & 16.335 & 0.232 \\
\hline 1 & 1 & 1 & 1 & 14 & 0.002 & 0.016 & 16.335 & 0.293 \\
\hline 1 & 1 & 1 & 工 1 & 15 & 0.024 & 0.101 & 16.382 & 0.357 \\
\hline $1 p$ & 1 & 1 & 1 & 16 & 0.054 & 0.019 & 16.626 & 0.410 \\
\hline 1 도 & 1 & 15 & 1 & 17 & -0.131 & -0.064 & 18.114 & 0.382 \\
\hline 1 단 & 1 & 10 & 1 & 18 & -0.099 & -0.081 & 18.991 & 0.392 \\
\hline 14 & 1 & 1 다 & 1 & 19 & -0.125 & -0.128 & 20.416 & 0.370 \\
\hline 1 & 1 & 1 & 1 & 20 & 0.066 & 0.008 & 20.823 & 0.408 \\
\hline 10 & 1 & I마 & 1 & 21 & -0.073 & -0.167 & 21.331 & 0.439 \\
\hline 1 & 1 & 14 & 1 & 22 & 0.049 & -0.061 & 21.563 & 0.486 \\
\hline 1 & 1 & 1 & 1 & 23 & 0.080 & -0.003 & 22.209 & 0.508 \\
\hline 14 & 1 & 10 & 1 & 24 & -0.108 & -0.124 & 23.405 & 0.496 \\
\hline 15 & 1 & 1 & 1 & 25 & -0.079 & -0.037 & 24.066 & 0.516 \\
\hline 14 & 1 & 14 & 1 & 26 & -0.104 & -0.075 & 25.248 & 0.505 \\
\hline 15 & 1 & 1 . & 1 & 27 & -0.053 & -0.088 & 25.561 & 0.543 \\
\hline 14 & 1 & 14 & 1 & 28 & -0.048 & -0.054 & 25.826 & 0.583 \\
\hline
\end{tabular}

Stationary study: We conduct Phillips Perron test (1988) and with the help of this program Eviews 5.1 we specify the number of delays to 3 , and this test is done through, estimate three models for Dickey -Fuller as follows nown as unit root tests:

The first model. This model is as follows:

$$
\underline{B} \text { acheCVS } S_{t}=\phi_{1} \text { BacheCVS }_{t-1}+\varepsilon_{t}
$$

Through the previous table we note that the value of PP cal is equal to -3.44 and comparing them with the tabular value of these statistical PP tab at the degree of freedom of $5 \%$, which is equal to -1.94 note that PPcal >PPtabl and therefore we reject the null hypothesis, that means that the time series of Tarpaulin is stable.

The second model. This model is as follows:

$$
\bar{B}_{\text {acheC } V S_{t}}=\phi_{1} \text { BacheCVS }_{t-1}+B+\varepsilon_{t}
$$

From the previous table we note that the value of PPcal is equal to -6.53 and comparing them with the tabular value of these statistical PP tab at the degree of freedom of $5 \%$, which is equal to -2.91 . Note that PPcal> PPtabl and therefore, we reject the null hypothesis, that means that the time series of Tarpaulin is stable.

The third model. This model is as follows: 


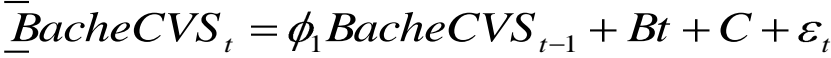

From the previous table we note that the value of PPcal is equal to -6.51 and comparing them with the tabular value of these statistical PP tab at a degree of freedom of $5 \%$, which is equal to 3.48-. Note that PPcal >PPtabl and therefore we reject the hypothesis nihilism roots and say that the sales chain for stable of Tarpaulin. We conclude that through previous statistical tests we say that the time series of Tarpaulin product is stable.

Model Identification. In order to identify the type model, we draw the simple and partial autocorrelation of the series CVS of sales as follows:

\begin{tabular}{|c|c|c|c|c|c|c|c|c|}
\hline Autocorr & relation & Partial Co & orrelation & & $\mathrm{AC}$ & PAC & Q-Stat & Prob \\
\hline I & 口 & 1 & 口 & 1 & 0.135 & 0.135 & 1.1527 & 0.283 \\
\hline I & 1 & 1 & 1 & 2 & 0.027 & 0.008 & 1. 1981 & 0.549 \\
\hline 1 & {$[1$} & 1 & 01 & 3 & 0.064 & 0.060 & 1.4613 & 0.691 \\
\hline 1 & 1 & 1 & 1 & 4 & 0.005 & -0.012 & 1.4630 & 0.833 \\
\hline I & I & I & I & 5 & -0.038 & -0.040 & 1.5606 & 0.906 \\
\hline I & 1 & I & 1 & 6 & 0.060 & 0.068 & 1.8097 & 0.936 \\
\hline 1 & 口 & 1 & 巨 & 7 & 0.144 & 0.132 & 3.2696 & 0.859 \\
\hline 1 - & I & I & 1 & 8 & -0.141 & -0.182 & 4.6886 & 0.790 \\
\hline 1 & 1 & 1 & I & 9 & 0.014 & 0.050 & 4.7021 & 0.859 \\
\hline $1 \square$ & I & $1 \square$ & I & 10 & -0.187 & -0.225 & 7.3133 & 0.696 \\
\hline$\square$ & 1 & $1 \square$ & 1 & 11 & -0.244 & -0.178 & 11.834 & 0.376 \\
\hline$\square$ & I & Iप & I & 12 & -0.241 & -0.206 & 16.327 & 0.177 \\
\hline 1 & 1 & 1 & I & 13 & -0.010 & 0.040 & 16.335 & 0.232 \\
\hline I & 1 & I & 1 & 14 & 0.002 & 0.016 & 16.335 & 0.293 \\
\hline I & I & I & ? & 15 & 0.024 & 0.101 & 16.382 & 0.357 \\
\hline 10 & 1 & 1 & 1 & 16 & 0.054 & 0.019 & 16.626 & 0.410 \\
\hline 1 든 & I & 10 & I & 17 & -0.131 & -0.064 & 18.114 & 0.382 \\
\hline 1 С & 1 & 10 & 1 & 18 & -0.099 & -0.081 & 18.991 & 0.392 \\
\hline 1 - & I & 1 다 & I & 19 & -0.125 & -0.128 & 20.416 & 0.370 \\
\hline 17 & 1 & 1 & I & 20 & 0.066 & 0.008 & 20.823 & 0.408 \\
\hline 10 & 1 & $1 \square$ & 1 & 21 & -0.073 & -0.167 & 21.331 & 0.439 \\
\hline 10 & 1 & 10 & 1 & 22 & 0.049 & -0.061 & 21.563 & 0.486 \\
\hline 1 & I & 1 & 1 & 23 & 0.080 & -0.003 & 22.209 & 0.508 \\
\hline 1 & I & 1 단 & I & 24 & -0.108 & -0.124 & 23.405 & 0.496 \\
\hline 10 & 1 & 1 & I & 25 & -0.079 & -0.037 & 24.066 & 0.516 \\
\hline 1 & 1 & 10 & 1 & 26 & -0.104 & -0.075 & 25.248 & 0.505 \\
\hline 10 & 1 & 10 & 1 & 27 & -0.053 & -0.088 & 25.561 & 0.543 \\
\hline 10 & I & 10 & 1 & 28 & -0.048 & -0.054 & 25.826 & 0.583 \\
\hline
\end{tabular}

Table 5 - Autocorrelation series CVS

We note that all autocorrelation located within the confidence intervals in addition to that the values of the coefficients is close to 0 so We're going to estimate the model using EVIEWS program, which minimize the Akaike and Schwarz standard.

Model diagnostic. Through the same previous table we test:

- First coeficiences test: For the model AR (1) (t student $=8.06>1.96)$ and therefore it differs from 0 , and also this is the case for the model AR (2) (t student $=2.90>1.96$ ). Besides, for the Form MA (1) (t student $=28.88>1.96$ ). the standard Akaike and Schwarz Akunan is in their minimum values.

- Residual test: Throughout this test, we will know whether residuals are a white noise, this is through the chart of the partial correlation function of the residuals ARMA model (2.1). Then we test the detection of knowing whether these residuals follow a normal distribution and that by drawing the histogram of the residuals and use of Jaque-Bera test: 


\begin{tabular}{|c|c|c|c|c|c|c|c|c|}
\hline \multicolumn{2}{|c|}{ Autocorrelation } & \multicolumn{3}{|c|}{ Partial Correlation } & $\mathrm{AC}$ & \multirow{2}{*}{$\begin{array}{l}\text { PAC } \\
0.011\end{array}$} & \multirow{2}{*}{$\frac{\text { Q-Stat }}{\text { 0.0079 }}$} & \multirow[t]{2}{*}{ Prob } \\
\hline 1 & $\mathbf{I}$ & 1 & $\mathrm{I}$ & 1 & 0.011 & & & \\
\hline I & I & I & I & 2 & -0.057 & -0.057 & 0.2072 & \\
\hline $\mathrm{I}$ & I & $\mathrm{I}$ & I & 3 & -0.031 & -0.030 & 0.2670 & \\
\hline $\mathrm{I}$ & I & $\mathrm{I}$ & I & 4 & -0.038 & -0.041 & 0.3608 & 0.548 \\
\hline $\mathrm{I}$ & I & 1 & I & 5 & -0.039 & -0.042 & 0.4612 & 0.794 \\
\hline 1 & I & 1 & 1 & 6 & 0.106 & 0.102 & 1.2190 & 0.748 \\
\hline $1 E$ & $\mathrm{I}$ & & 1 & 7 & 0.119 & 0.112 & 2.1888 & 0.701 \\
\hline 14 & 1 & 1 & 1 & 8 & -0.089 & -0.085 & 2.7414 & 0.740 \\
\hline & $\mathbf{I}$ & 17 & I & 9 & -0.054 & -0.039 & 2.9495 & 0.815 \\
\hline 10 & 1 & 14 & 1 & 10 & -0.066 & -0.064 & 3.2640 & 0.860 \\
\hline I & $\mathbf{I}$ & 17 & I & 11 & -0.015 & -0.007 & 3.2804 & 0.916 \\
\hline 1 t & 1 & 14 & $\mathbf{I}$ & 12 & -0.056 & -0.074 & 3.5176 & 0.940 \\
\hline $\mathrm{I}$ & 1 & 17 & 1 & 13 & -0.005 & -0.044 & 3.5194 & 0.966 \\
\hline I & I & 0 & I & 14 & -0.037 & -0.050 & 3.6306 & 0.980 \\
\hline I & I & 1 & I & 15 & 0.010 & 0.030 & 3.6384 & 0.989 \\
\hline 1 & I & 15 & I & 16 & -0.048 & -0.045 & 3.8278 & 0.993 \\
\hline 10 & 1 & 10 & 1 & 17 & -0.076 & -0.077 & 4.3126 & 0.993 \\
\hline 1 & $\mathrm{I}$ & 10 & 1 & 18 & -0.054 & -0.064 & 4.5620 & 0.995 \\
\hline 1 & 1 & 17 & 1 & 19 & -0.040 & -0.043 & 4.7013 & 0.997 \\
\hline 1 & $\mathrm{I}$ & 1 & I & 20 & -0.064 & -0.085 & 5.0775 & 0.998 \\
\hline 13 & I & 1 五 & 1 & 21 & -0.066 & -0.099 & 5.4887 & 0.998 \\
\hline 1 & 1 & 17 & 1 & 22 & -0.009 & -0.053 & 5.4964 & 0.999 \\
\hline 1 & 1 & c & 1 & 23 & -0.039 & -0.049 & 5.6464 & 0.999 \\
\hline 1 & 1 & 1 & I & 24 & -0.007 & -0.021 & 5.6514 & 1.000 \\
\hline
\end{tabular}

Table 5 - Autocorrelation Of Residuals Statement

Note that all borders are located in the critical region, which shows a lack of autocorrelation of the residuals, in addition to this, all the possibilities for statistical Ljung Box $(Q$, stat) is greater than $5 \%$, which leads us to accept the hypothesis that the residuals follow the process white noise.the following histogram of the residuals and use Jaque-Bera test explains this result:

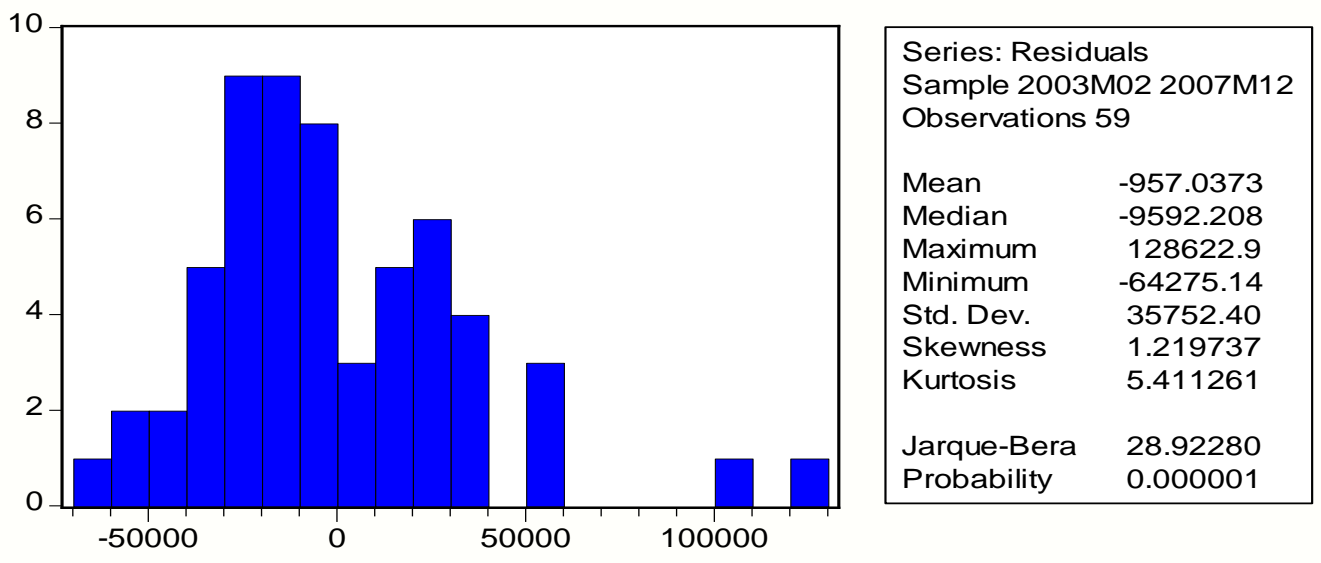

Figure 3 - Histogram of the residuals

It is noticed through the histogram of the residuals that it is symmetrical for the zero to some extent, when statistically test Jaque- Bera, we notice that JB $=28.92>$. But in spite of that, we say that the model remains statistically acceptable.

\section{RESULTS AND RECOMMENDATIONS}

Throughout the above study, we have tried to develop statistical models for modeling achieved sales of each product which are deemed acceptable statistically. This does not prevent the existence of errors in the estimates or expectations which require audits and improvements because these models remain a support helping managers thru decisionmaking. Therefore, one can suggest some recommendations and suggestions on this institution as follows: 
- The institution needs to establish a system to predict the level of sales to avoid dangers caused by high competition in the Algerian market and unexpected changes.

- Relying on statistical and mathematical methods to help them make the best decision at the right time in order to maintain good relations with customers and gain their loyalty.

- The need for the introduction of analytical accounting in the organizational structure of the institution to be able to analyze the costs which lead to reduce the loss of scarce resources and thus maintaining production costs at a lower level.

- Organizing the sale prices of products and access to gain consumers' satisfaction

- Employ experts and competent decision makers in the standard analysis and operations research to carry out the prediction based on statistical models.

- The use of modern software used in the sales modeling and forecasting.

\section{REFERENCES}

1. A.Bensabr.B.Bleuse.»Pratique des chroniques de la prévision a court terme». Trillon. Masson. Paris Milan.Barcelone. Mexico1989.

2. ANDERSON, O. D."Time Series Analysis and Forecasting: The Box-Jenkins Approach", Butterworths, London (1976),.

3. Bernard rapacchi «Analyse des séries chronologique», centre de calcul de Grenoble, 1993

4. BROZE, L. et MELARD, G. "Exponential smoothing: estimation by maximum likelihood" The Journal of Forecasting, 9, $n^{\circ} 5,445-455.1990$.

5. C.W.J.GRANGER et PAUL NEWBOLD "Forcasting economic times series" $2^{\circ} \mathrm{Ed}$. Acadimic press, INC California 1986

6. Charpenter A «séries temporelles, théorie et application» université de Paris Dauphine, vol 2,2003,

7. G.Chevillon» pratique des séries temporelles», université d'oxford ; Londres ;2004

8. G.S.Maddala «introduction to econometrics» Macmilian publishing company.New York 1992.

9. M.C Viano, A.Philippe «économétrie des séries temporelles» université des sciences et technologique de Lille, France 1999.

10. R.Bourbonnais M Terezza «analyse des séries temporelles en économie» 1 édition presse universitaire de France, 1998. 